\title{
A DRIFTER OF DADAIST PERSUASION
}

\author{
MATILDE MARCOLLI
}

\section{Mathematics through Abstract Art}

sors immanis et inanis, rota tu volubilis

1.1. Abstractions. Both my parents were very deeply involved in the scene of Italian contemporary art, over the span of several decades. Both of them studied Architecture in the late 1950s and early 1960s at the Politecnico in Milan. My mother, who had been a student Ernesto Nathan Rogers, collaborated with some of the most visible figures in architecture and graphic design of the time: Konrad Wachsmann, Ignazio Gardella, Albe Steiner. My father became a colleague of Umberto Eco and Tomás Maldonado at the experimental university program in the arts, the DAMS of Bologna. My parents were also painters, and their art was frequently inspired by mathematical themes (Figure 1 and Figure 2). In the 1970s, both before and after my parents divorced, our house was frequented by a circle of artists, designers, and various communist intellectuals. I grew up surrounded by contemporary art, well versed in its history and meaning. I grew up listening to atonal 20th century classical music: by the time I was in my early teens, my favorite composers were Luciano Berio, Luigi Nono, Karlheinz Stockhausen, Iannis Xenakis, Giacinto Scelsi, Pierre Boulez. Later in my teens I discovered early music: Carlo Gesualdo, Luca Marenzio, Orlando di Lasso. I never came to terms with the Romanticism, which remains incomprehensible to me to this day. My taste in the visual arts was largely influenced by the artistic movements that surrounded me in my early years: my father's Abstractism was close to the currents of Op Art and Kinetic Art and to the Ulm school of Design. My mother's Conceptual Art was informed by Dadaism and Minimalism, and by Semiotics. I could relate deeply to the Russian Avant-garde and the painters of the Bauhaus period, as well as to the Abstract Expressionism of postwar America.

1.2. Doleful shades. While extremely stimulating at the intellectual level, the environment I grew up in was also a dark and violent world. I have partly depicted it in the semi-autobiographical commentaries In the Wells of Silence, first written in blog form and then made available as [8]. I am returning to this theme with a novel in preparation, The rape of Europa and the mirror of Narcissus, [15], based on a partly fictional and partly real epistolary exchange between some of the cultural and personal figures of the time, and an exploration of the connections and parallels between that world of artists and the world of mathematicians I later experienced.

Regions of sorrow, doleful shades, where peace

And rest can never dwell, hope never comes

That comes at all.

(John Milton, "Paradise Lost", I, 65-67) 


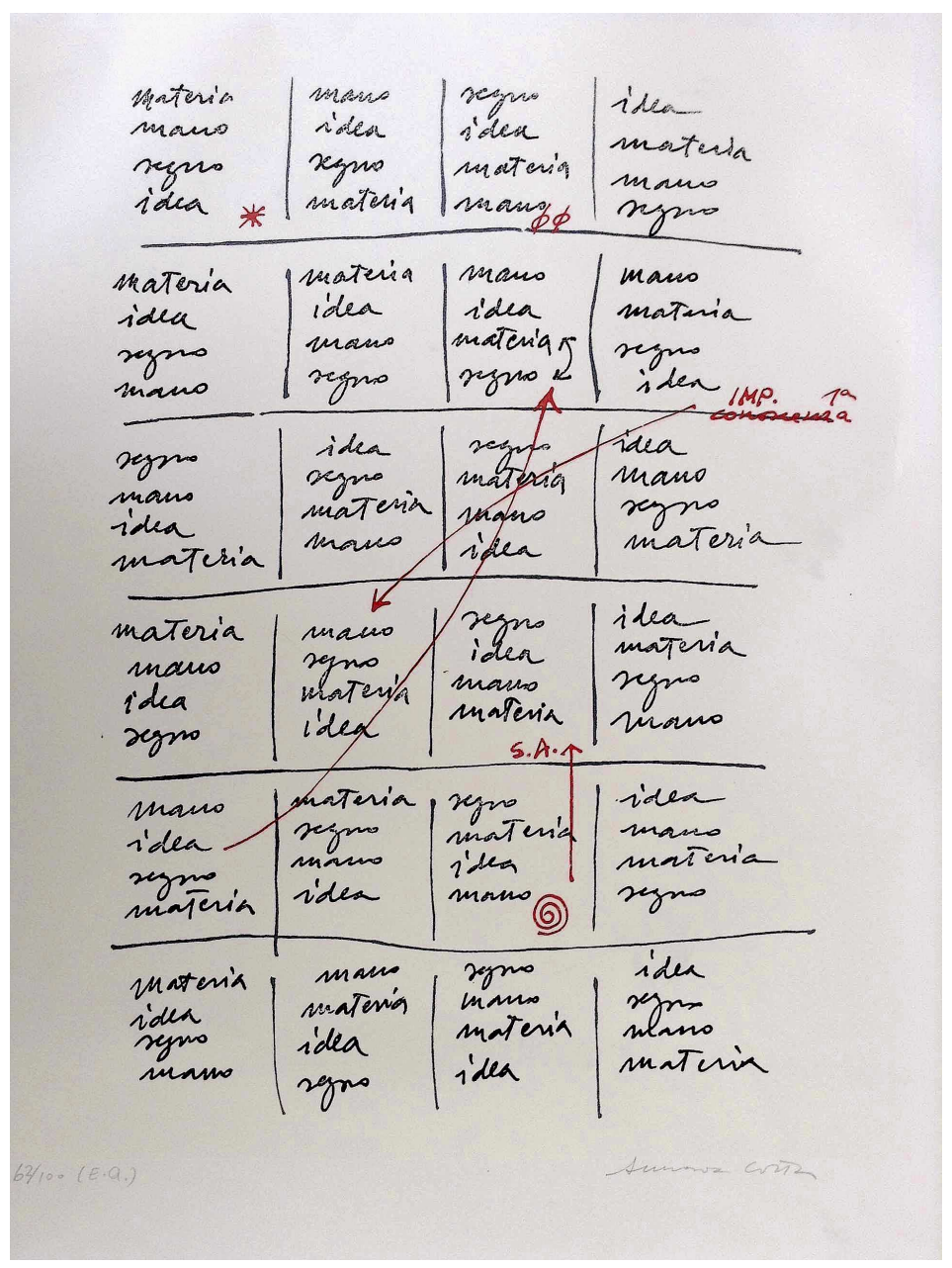

Figure 1. Annarosa Cotta, Segni, 1986.

1.3. Progressions. At the same time, while I was living in this artistic milieu, I developed a keen interest in the hard sciences. My mother, who had initially been a Chemistry student, retained a deep passion for science throughout her life and infected me with it from a very early age. Historically, we lived still deeply embedded in the framework of the Cold War. In those years Physics had taken center stage among the sciences and was hailed as the harbinger of progress and civilization. It was the Space Age and humanity was lifting itself off the uncertain future of this planet to conquer the unknown. I discovered how that same dream of technological and scientific progress, of conquering the depths of the cosmos, had its roots planted in the same ground that gave rise to the blooming of Modern Art: the scientific Konstantin Tsiolkovsky and the mystical Biocosmists had all been breathing the same inflamed atmosphere of Velimir Khlebnikov, Mikhail Larionov and the Futurists. 


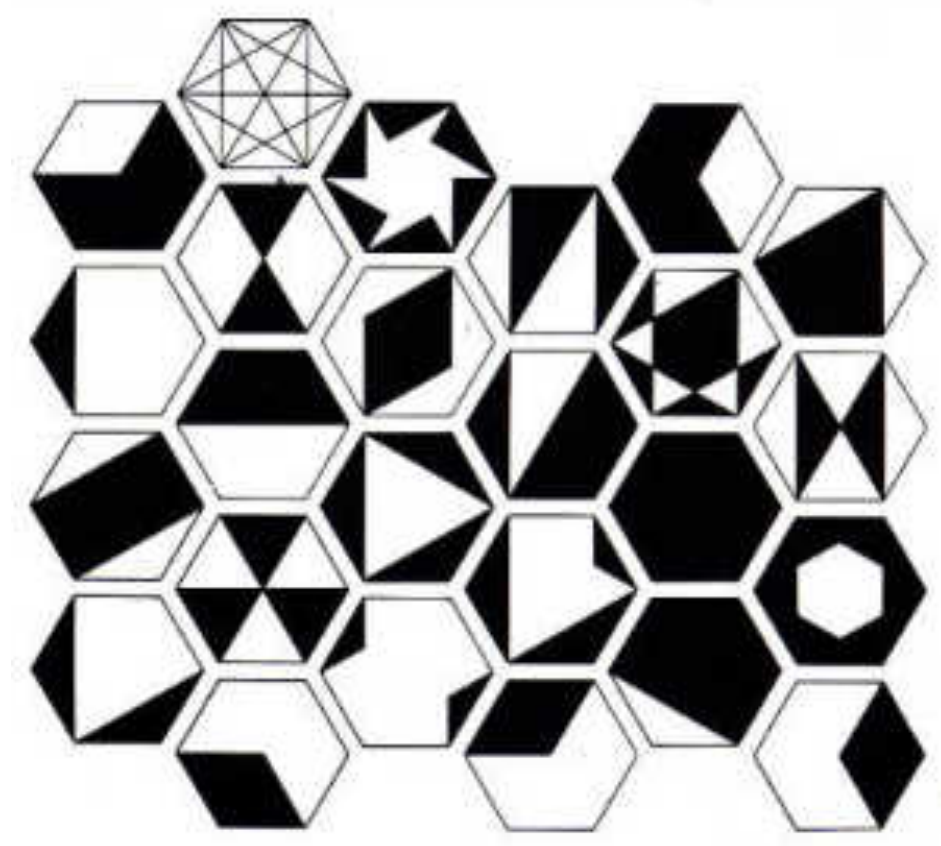

Figure 2. Attilio Marcolli, Struttura Segni, 1985.

1.4. Primum Movens. I gradually came to understand that what I found deeply moving in an abstract painting, like Kandinsky's "Several circles", or in a piece of atonal classical music, such as my long time favorite "Le marteau sans maître" by Boulez, is the contemplation of the beauty of structures. Abstract art is about abstract structures, and so is mathematics. I became more directly interested in mathematics during my teenage years, when I became convinced that art and mathematics were just slightly different ways of expressing the same concepts.

I got to reading a large supply of advanced mathematics and physics textbooks, generously made available in Italy, at political prices, by the Soviet publisher Mir. This balanced my school education in a Liceo Classico, which was largely centered on the traditional humanistic curriculum: in depth learning of Ancient Greek and Latin, Philosophy, Art History, but with very little exposure to science and to anything modern. To be fair and honest, a good knowledge of a couple of ancient Indo-European languages served me good when, in much more recent days, I got seriously interested in working in Linguistics, so I have no regrets about that strange mixture of humanities and hard sciences. My learning of mathematics and physics was very idiosyncratic, being mostly based on which Russian books I could get my hands on next through the local section of the Party, but it served some purpose, and when I enrolled as a physics student at the University in Milan, I sailed through it smoothly. Serendipitous encounters with books remained the primum movens behind much of my scientific work over the years, now seriously threatened by the rapid disappearance of so many good bookstores. 


\section{Mathematics, Violence, and the language of Surrealism}

nunc obdurat et tunc curat ludo mentis aciem

2.1. The Millenarian Astronaut. Curiously, when it came to actively use art as a form of expression, I did not choose the abstract art that I so much loved (to which I returned only much more recently), but I preferred the language of Surrealism, and especially the collage techniques of Max Ernst. Surrealism had been the other face of the Avant-garde, its darker, oneiric, inner-looking, psychoanalytic, and at times disturbing face, counterposed to the radiant, rational, solar and forwardlooking face of Abstraction. Max Ernst, with his elliptic language of frottage, his half spoken, tongue-in-cheek references to science as a mysterious alchemy, was always my favorite Surrealist. I pondered long hours over the dream-like narratives of the composite images in his famous Collagenromane, especially "Une Semaine de Bonté", but also some of the lesser known ones of his later years, like "Journal d'un Astronaute Millenaire" and "Maximiliana, or the illegal practice of Astronomy".

2.2. Bonté et cruauté. I chose Surrealism as my favorite mode of artistic expression when it came to finding words and images that would relate to my experience of the world of Mathematics. I believe I was also attracted to it in an attempt to portray the striking contrast between the apparent Apollonian beauty of mathematics, and the darker and violent world that lies beneath its untroubled external surface. My friend Yuri Manin once said that "Surrealists are interesting (and for me, repellent) exactly because they stopped pretending and sort of simple-mindedly made propaganda for pure artistic values of cruelty". There is an element of truth in this observation: Surrealism, and in particular some of the earlier collage-novels of Max Ernst like "Une Semaine de Bonté", are also depictions of violence and cruelty. Violence exists and one encounters it frequently, even within the ethereal realm of mathematical abstractions. Pretending not to see it will not make it go away. I submit that it is of crucial importance to have a language that makes it possible to speak poetically and artistically about violence. It is the only possible way to face and express that which cannot be openly spoken about in the community, just as the Surrealists in the early 20th century were able to speak freely, through their collage images, about the violence intrinsic in traditional family and bourgeois society. Violence, bullying, and intimidation exist and are practiced on a daily basis within the mathematical community, and there is a widespread "culture of cruelty" among its practitioners, but it is incredibly difficult to even find a venue where such issues can be openly discussed. Art can help portraying the sharp contrast that exists between the high hopes and dreams, and the reality on the ground.

2.3. Triptych. I will discuss here only one example of my Surrealist artwork, the piece called Triptych, which dates back to 1995. This is a portrait of my early days in the world of Mathematics and my perception of its functioning. The left panel of the Triptych (Figure 3) aims at representing the hidden side of the mathematician's work, the patient, difficult, often painful struggling with a dense resistant prima materia, not yet fully understood, not yet fully formalized. This work does not happen in the sunlight, but in a dark basement, hidden from view, and yet it 


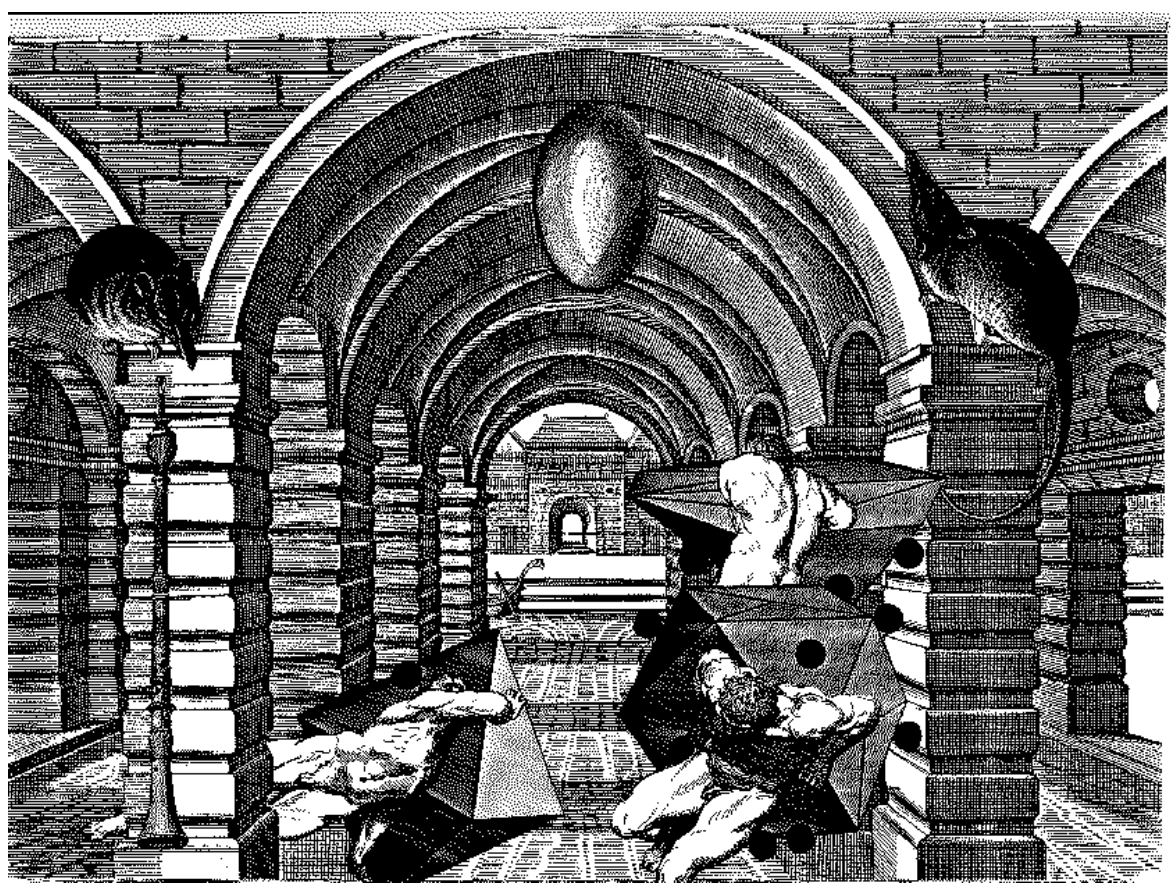

Figure 3. Matilde Marcolli, Triptych, left panel, 1995.

is often the really crucial part of the work, the laboratory of ideas, the alchemical vessel where reactions finally occur. The symbolism in the left panel is quite evident: the struggling figures, reminiscent of a scene of Dante's Inferno, represent the effort that is required in order to move the stones, here in the form of a puzzling mathematical observation about polyhedra that occurred in a study of $\mathrm{PGL}_{2}$-orbits of points (a toy model for the more difficult problem of orbits of curves), that may partner, Paolo Aluffi, was investigating at the time. The rats point to an underground environment, chaotic and unclean, where ideas are not yet polished, not yet rendered palatable to the official standards of rigor. The musical instrument and the egg shape (a reference to Piero della Francesca's Madonna di Brera), as well as the Renaissance city in the background, point instead to the harmony and beauty hidden behind the weariness and fatigue that are central to the image. I regard this unseen, unpolished world as the real heart and soul of mathematics, its true essence beneath the surface of appearances.

By contrast, the right panel (Figure 4) depicts a very different side of the mathematician's world, the one that happens above the surface, in an open space of urban landscape scorched by the light of several (higher genus) suns. A world I was for the first time becoming aware of, by observing the behavior of the dominant alpha males of the high profile academic environment I now inhabited. This world is no longer connected to the intimate, solitary, painstaking, underground work, the difficult but ultimately rewarding mining for mathematical truths, unseen to all but oneself and often not recognized. This is the flashy limelight of the prominent social environments within the mathematical community. As a social scene, 


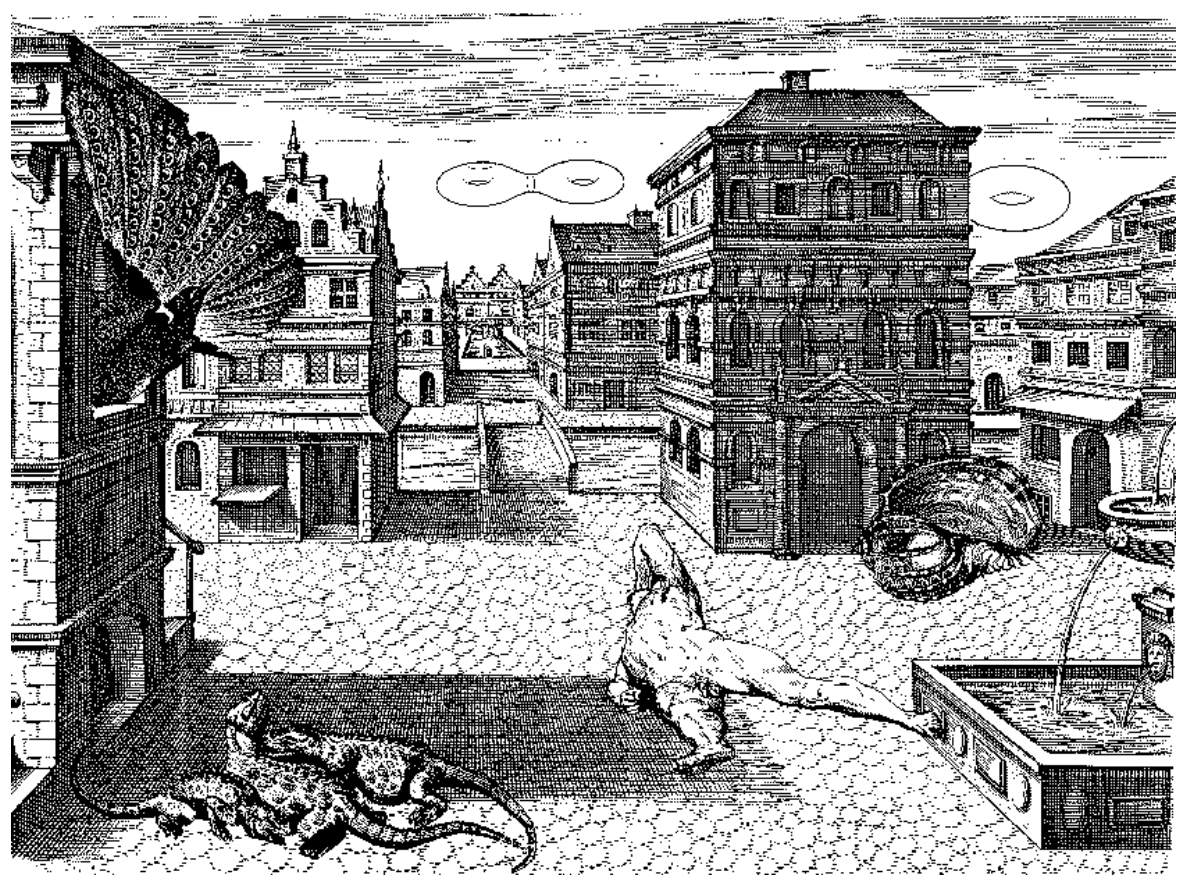

FiguRE 4. Matilde Marcolli, Triptych, right panel, 1995.

it presents itself rather like a desolate landscape, which only has room for peacockstyle self-aggrandizing narcissism and for reptilian aggressive territoriality, as well as for spasms of human despair. A symbol of harmony and beauty, the sea shell, is present on this side of the panel as well, as a reminder of the existence of beauty in mathematics, even amidst the barren desolation that characterizes the social world of its adepts and their interpersonal interactions.

The central panel (Figure 5), framed by the geometry of perspective, portrays a difficult mediation between the personal past and future, but also more broadly between brutality (the skinned human figure on the stairs) and tenderness (the kittens nearby). In order to be able to continue working as mathematicians we need to protect our capacity for wonder, our innocence in looking at the intrinsic beauty of things: protect it from being brutalized and destroyed by the culture of bullying and violence that pervades the community. There is a paradox in this difficult quest for equilibrium, almost like an impossible figure hidden in a realistic perspective: in order to protect our inner peaceful vision, we need to become callous fighters on the outside (hence the armor and weapons). Whether we may be able to successfully continue to exist as mathematicians largely rests on the question of whether it is indeed possible to maintain or not such a precarious balance.

\section{A Long March via Random Walks}

nunc per ludum dorsum nudum fero tui sceleris 


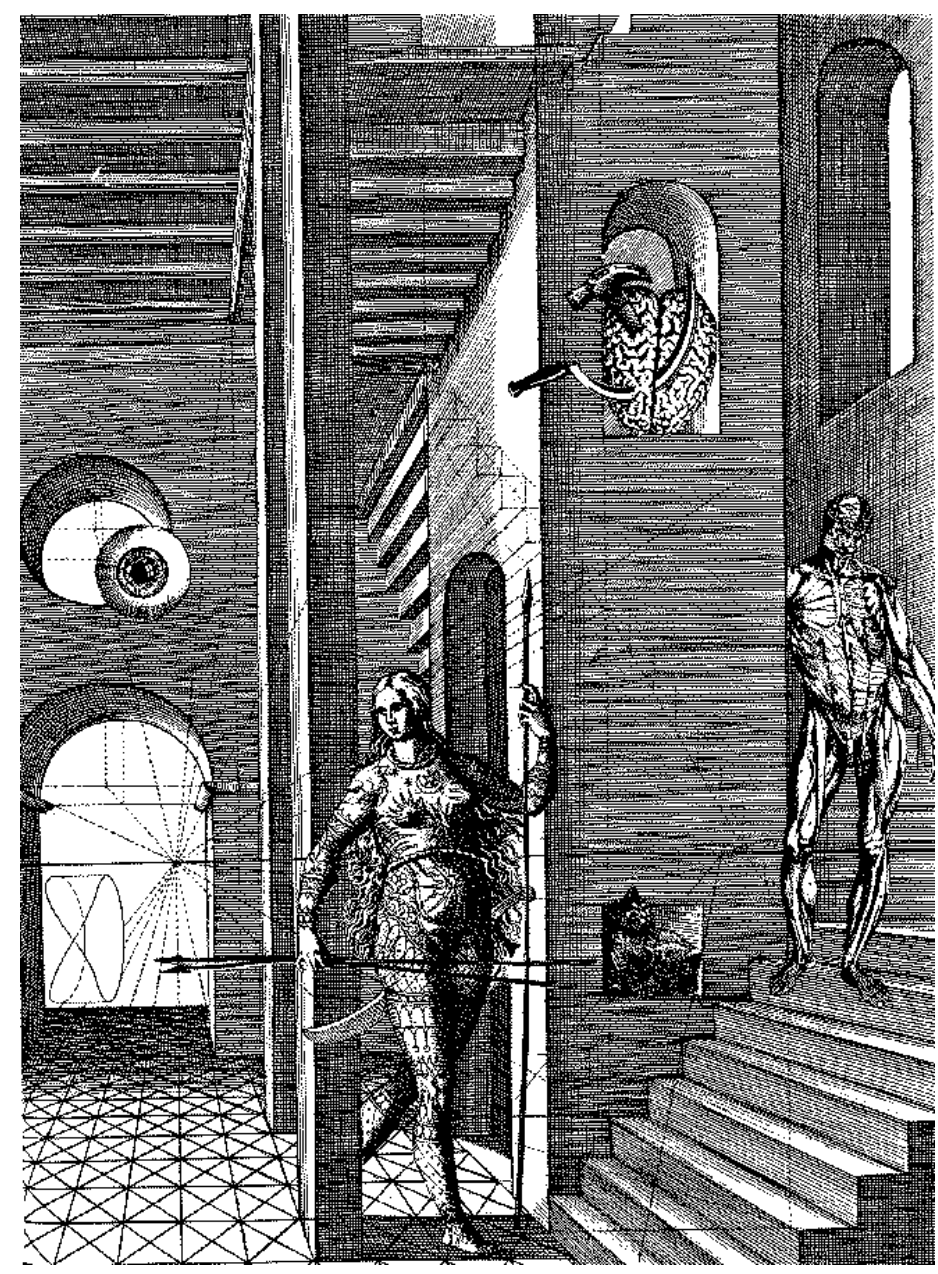

Figure 5. Matilde Marcolli, Triptych, central panel, 1995.

3.1. Physicist and Topologist. My professional itinerary through Mathematics and Physics was far from linear and untroubled. During the years 1989-1993 I was enrolled as a Physics student at the University of Milano, a full immersion exposure to mathematics and theoretical physics. I found there a very stimulating intellectual environment, an open and warm relation between faculty and students, and an enthusiastic group of close friends with whom we spent long retreats in the mountains, studying mathematical analysis and quantum physics, drinking wine, playing music.

In that same period I also wrote my collection of short stories with mathematical themes, Racconti per il Lupo, recently made available as [10], about which I already wrote extensively in [1]. The short stories in [10] are accompanied by my first Surrealist collage-novel, Lupus in fabula, which I also discussed in [1].

While still a student, I was half-promised a job as a physicist at an Institute for Informatics Systems in Russia, but by the time I graduated the Soviet Union 
had collapsed and my perspective job had all but vanished. I hanged around in Italy for a couple more months, until I was unexpectedly admitted by Peter May to graduate school in mathematics at the University of Chicago, after a talk I gave at a topology conference. Before I could think much about it, I was living in another continent. At first, adjusting to life in the US was difficult, as any major unplanned change of living conditions is bound to be, but I gradually came to accept that there was nothing to go back to (especially after my mother's death in 1996). My new identity as a topologist, and my new life and long term personal relationship with my partner, Paolo, whom I met during my first year in Chicago, provided a new and promising view of a possible future.

3.2. Gauge theory in Wonderland. I graduated from the University of Chicago in 1997, with a thesis on the then very fashionable Seiberg-Witten gauge theory and 3-manifold topology. My PhD supervisor, Mel Rothenberg, was a warm and inspiring figure. We shared that old belief in a progressive future for humankind, which was rapidly disappearing in the Old Continent, and I greatly appreciated the complete freedom he gave to his graduate students to pursue whatever projects stimulated their passion and curiosity. I came from a good exposure to gauge theories in the theoretical physics context, and I found it natural to shift to mathematical research by investigating the mathematical side of gauge theory, its spectacular success, since the ' $80 \mathrm{~s}$, in constructing invariants of low dimensional manifolds. I found it incredibly beautiful that the behavior of solutions of the classical equations of motions of fields governing elementary particle physics would be able to distinguish the smooth structure of the underlying spacetime manifold. Conceptually it reveals the profound interconnectedness of physics and geometry, at a mathematical level that is far deeper than physical intuition. It was beautiful. It is beautiful, an amazingly beautiful story. What was far less beautiful was the reality of working in the field, the way the power relations played themselves out within the very small community of mathematicians working in this area of research. I only became aware of this darker side of my favorite mathematical subject when I moved on to my first job, a three year postdoc at MIT. I was on top of the world at the time: I viewed it as the best opportunity to learn from the leading experts in the field, in one of the most active and most exciting mathematical communities in the world. It looked as if my transition from physics to mathematics, as well as my adjustment to the American academic world had been successfully completed.

3.3. Into this wilde Abyss. Reality was far remote from the imagination: while the environment appeared friendly on the personal level, professionally talking to people proved impossible, exclusion and isolation were complete and unquestionable, and within that couple of years, certain subtle hints that I should move out of the field, and preferably out of mathematics altogether, became deafening roars. I still managed to finish the 200 pages long paper with Bai-Ling Wang on SeibergWitten Floer homology, and to write my first book, an introduction to SeibergWitten theory. I also collaborated with Varghese Mathai on the noncommutative geometry of the Quantum Hall Effect, a side project at the time, but one that played an extremely important role, as it served as my first introduction to another field of research, which was to become my escape route not long afterwards. Fortunately, all this work lead to something and, during my second year at MIT, I was offered a new unexpected opportunity, which I immediately grabbed: a no-teaching 
long-term research job at the Max-Planck Institute for Mathematics in Bonn. I finished my third and last year at MIT, increasingly at odds with the surrounding culture of cruelty. In 2000 I left Boston, a city I greatly enjoyed, and I relocated: another unexpected and unplanned change in the course of life, another uneasy adjustment. I spent most of the following years traveling: back and forth, trying to maintain a family life in the US and a job in Europe, and then increasingly more and more traveling to conferences and exhausting lecturing tours across continents. I left gauge theory behind. Much as I loved the subject, there was no way of ever getting past the exclusion wall I encountered. The human environment had become so difficult as to make it impossible to work with the right peace of mind that is necessary to produce good, or even acceptable, mathematics.

During the last few months I spent at MIT, I also wrote my first science fiction novel, City of Sorrow, recently made available [3]. I finished writing it during the first month of my stay at the MPI. I'll return to say a few words about it in the next section.

Into this wilde Abyss the warie fiend

Stood on the brink of Hell and look'd a while,

Pondering his Voyage

(John Milton, "Paradise Lost", 917-919)

3.4. The Magic Mountain. The MPI was one of the most fortunate choices of my life. I could heal, I could learn new things, and I discovered that there is plenty of mathematical beauty beyond gauge theory. Most importantly, I discovered that there is no harm in exploring new territories. The mathematical community, especially in the US, is so profoundly territorial that every theorem lies buried in a barbed wired corner of the landscape, generally inaccessible to all, except for a few self-appointed keepers of the gate. Trespassing beyond one's assigned boundaries is severely punished. Are you a topologist or an algebraic geometer? A geometer or an analyst? A mathematician or a physicist? What are you? What is your field? The MPI was a different world.

Deeply informed by the Russian school of mathematics, which still provided the majority of the Institute visitors in those years, the MPI functioned as an open unstructured space of interaction. Activities revolved around the many weekly seminars. Although some of them were marked by field (Number Theory Seminar, Topology Seminar) others took on a much broader perspective, like Manin's "Algebra, Geometry, and Physics Seminar", or the Oberseminar, which functioned as a Colloquium style lecture. Most importantly, all interactions were completely informal and everybody was on the same ground, sharing offices and common spaces, freely discussing. There was no sense of a tribal subdivision of knowledge into fenced territories.

I quickly began collaborating with Yuri Manin on a fascinating mixture of number theory and noncommutative geometry, which started with our paper on the limiting modular symbols. Our collaboration, which continues to these days, was one of the best experiences I had in my entire mathematical career. Not only I learned an enormous amount of new things, but I also finally experienced the act of doing mathematics in the way I had always desired it to be: a peaceful, 
profound, intellectually rewarding activity, completely free of all the dark and violent undertones I had so frequently encountered elsewhere. If I have remained a mathematician for so long, it is largely because of the positive influence of that collaborative experience.

As I grew more confident into this new field of research, I wrote my second monograph, Arithmetic noncommutative geometry, in the informal style of a lectures series, aimed at introducing the combination of noncommutative geometry, number theory, and arithmetic geometry to a broader public of mathematicians.

At around the same time I also wrote my second science fiction novel, Yamaon, [4], which tackled my inner reservations and fears, largely coming from personal and family history, about living in Germany, and provides a humorous portrait of the MPI atmosphere. It also aims at showing how the memory of the second world war still determines, half a century later, the feelings and worldview of so many Europeans.

3.5. No light, but rather darkness visible. My last years of MPI experience took on a very different flavor, mostly due to two independent developments, one in the surrounding environment and one within my own research and personal life. The MPI had started to change, and it changed even more drastically a few years after I left, almost entirely losing the special atmosphere I remember from the late ' 90 s and the early years of the new century. One of the first significant changes was the decision to start a graduate school, something the institute was clearly not designed for. The existence of a graduate school generated inevitable friction between the informal, unstructured, generally anarchic and highly international atmosphere of research at the MPI and the rigid, hierarchical, ethnically homogeneous, and usually extremely formal nature of the rest of the German academic world. I graduated sixteen PhD students to this day: all but two of them have at some point passed through the MPI, so I experienced the best and the worst of that system of graduate education. My decision to return to work in the US and leave what would have otherwise been a dream job at the MPI was largely a consequence of that experience.

The other significant change of perspective occurred when I started to get more closely involved with a new community of mathematicians, revolving around the field of Noncommutative Geometry. The experience was, at the mathematical level, interesting and gratifying, but the community was tragically infected by group think, personality cults, and narcissistic abuse. The work I did in those years, often in collaboration with Alain Connes, with whom I wrote my third monograph, Noncommutative Geometry, Quantum Fields, and Motives, seemed to provide just the right combination of mathematics in various flavors (geometry, number theory) and of theoretical physics that I had been looking for. For a few years I thought I had found a suitable environment where creativity could flourish. I have described that illusion at length in my theater play, The Somber Science, [9]. By the time I was finally declared persona non grata and unceremoniously and brutally expelled from that community, I had seen enough of it to realize, once again, how yet another field full of beautiful mathematics can be marred by a profoundly dysfunctional human environment.

A reflection on the difficult experience of those years is articulated in the collections of short commentaries in Heart in the Machine, [5], and Screams of Metal, [6], which are edited versions of postings of the blog Welcome to the Machine. I 
also depicted the experience of my past few years at the MPI and the relocation to Caltech in the theater play, The Somber Science, written in 2009, [9].

Yet from those flames

No light, but rather darkness visible

(John Milton, "Paradise Lost", I, 62-63)

3.6. Attrition warfare. I relocated in California in the summer of 2008. Caltech is an ideal place, with a very small number of students and a low teaching load, a small faculty body, which allows for easy communication, and with almost nonexistent bureaucracy. It was an ideal place for me to heal and to attempt to reinvent myself, one more time, as a mathematician and physicist. It was a very long and difficult healing process which is still ongoing today. The closure of the wonderful scientific bookstore at Caltech and the successive "restructuring" of the library that made most books inaccessible were a dramatic and unexpected debacle in this slow progress. I had counted on those resources in order to try to reestablish my research identity with new directions and new projects. Reading books is for me the only dependably unbiased and nonviolent form of mathematical communication. Losing my most precious ally and reliable source of information made my recovery process enormously more difficult and slow.

I am trying to portray the importance books had in shaping the course of my intellectual life over the years, and as an instrument of healing in the times of deep crisis, in one of my ongoing literary project: Encounters: a narrated library, [16], while another blog journal covering the first few years of my Californian life, Listening to Golem, has now been made available in book form, [7]. The collection of poems Street Science, [2], written in 2013, about which I already wrote in [1], also deals with my experiences during this period and with an overall bird eye view of the twenty years I spent doing mathematics. In another ongoing literary project, Voyage through the Night: Opus Rubrum, [13], I am editing a journal of dreams covering the years 2009-2013, where the experience of the mathematical world is revisited from the alchemical archetypal perspective of the world of the unconscious psyche, based on my long acquaintance of nearly twenty years with the Jungian school of analytical psychology and with Carl Gustav Jung's writings.

During the six years I spent so far at Caltech I was forced by circumstances to undergo a profound restructuring of my research work. I tried to salvage what I could of the ongoing projects I had at the time when I left the MPI, when the noncommutative debacle took place. I reduced many long term projects in size, turning them into short term goals I could work on with students, so that they would at least serve some educational purpose. I attempted to reinvent myself in new directions.

Primarily I focused on the relation between motives and quantum field theory, a new subject I had contributed to create in previous joint work with Alain Connes. Focusing now on more algebro-geometric aspects of the subject, I found a topic on which I could collaborate with my partner Paolo, after so many years. It helped me greatly at that time of difficult transition, until that work also came under attack in yet another territoriality claim made by a couple of other prominent players in the field. So a field I had seen growing from the very beginning quickly became another barren barbed wired landscape, another exclusion zone I was forced to abandon. 
I hit the road again. Thanks to a new collaboration with Goncalo Tabuada, I learned a lot about motives and dg-categories. In another direction, I experimented with information theory, first continuing the collaboration with Yuri Manin, using quantum statistical mechanical methods to study the asymptotic bound for error correcting codes, and then with some of my students, exploring entropy, computation and renormalization, geometry and quantum information. Finally, I just started thinking about Computational Linguistics as a new research area I would like to get actively involved with. The quest for a Utopian place in the landscape of human knowledge that would finally provide a peaceful and nonviolent environment where I may be able to work in peace is probably, like all Utopias, bound to reveal itself as another Fata Morgana of the mind, but the continuing voyage in search of its shores has certainly guided me across many interesting terrains.

I tried to learn and teach Sanskrit. I lectured in local bookstores about Art and Mathematics, leading to an ongoing collection of essays, [11], [12]. I sold all my writings at the Bay Area Anarchist Bookfair. I was trying to find ways to divert my mind from the exhausting ongoing attrition warfare on the front of research work, to channel its desire for creative expression towards more peaceful environments.

Over the six years I spent at Caltech so far, I worked on 53 new research papers, spread across different fields between mathematics, physics, and information theory, and I wrote one more monograph, Feynman motives, on the occurrence of motives of algebraic varieties in quantum field theory. However, I have recently come to realize that pressing on the accelerator did not really help the healing process, and that perhaps it is Art much more than Mathematics, at this stage, that is likely to offer a meaningful perspective on this whole experience and to provide a way to find the right state of mind to move forward. In order to produce good Mathematics, one needs the right peace of mind. Continuing to work in hostile environments only leads to poor quality results. It is far better to move on, as I so often did, in search of some, at least temporary, respite. I have repeatedly used Art, during such periods of change, as a way to cope: it helped me survive the Absurd.

Who overcomes

by force, hath overcome but half his foe

(John Milton, "Paradise Lost", I, 648-649)

3.7. The illegal practice of cosmology. One of the topics I experimented with in the last few years is geometric models for cosmology, in collaboration with an old friend from my physics student days in Italy, the cosmologist Elena Pierpaoli, and with two of my graduate students. We produced a few papers, until the growing friction with the noncommutative geometry establishment forced us to stop.

One morning I met my cosmologist colleague Marc Kamionkowski at the campus coffee shop, and he jokingly asked me if I was "practicing cosmology without a license". I was immediately reminded of Max Ernst's "The illegal practice of Astronomy" and I began a composition, [17], still in preparation, with title "The illegal practice of Cosmology", mixing poetry and abstract art (Figures 6 and 7).

Meanwhile, my unorthodox mathematical cosmology landed me a Distinguished Visiting Research Chair and the Perimeter Institute for Theoretical Physics, in 


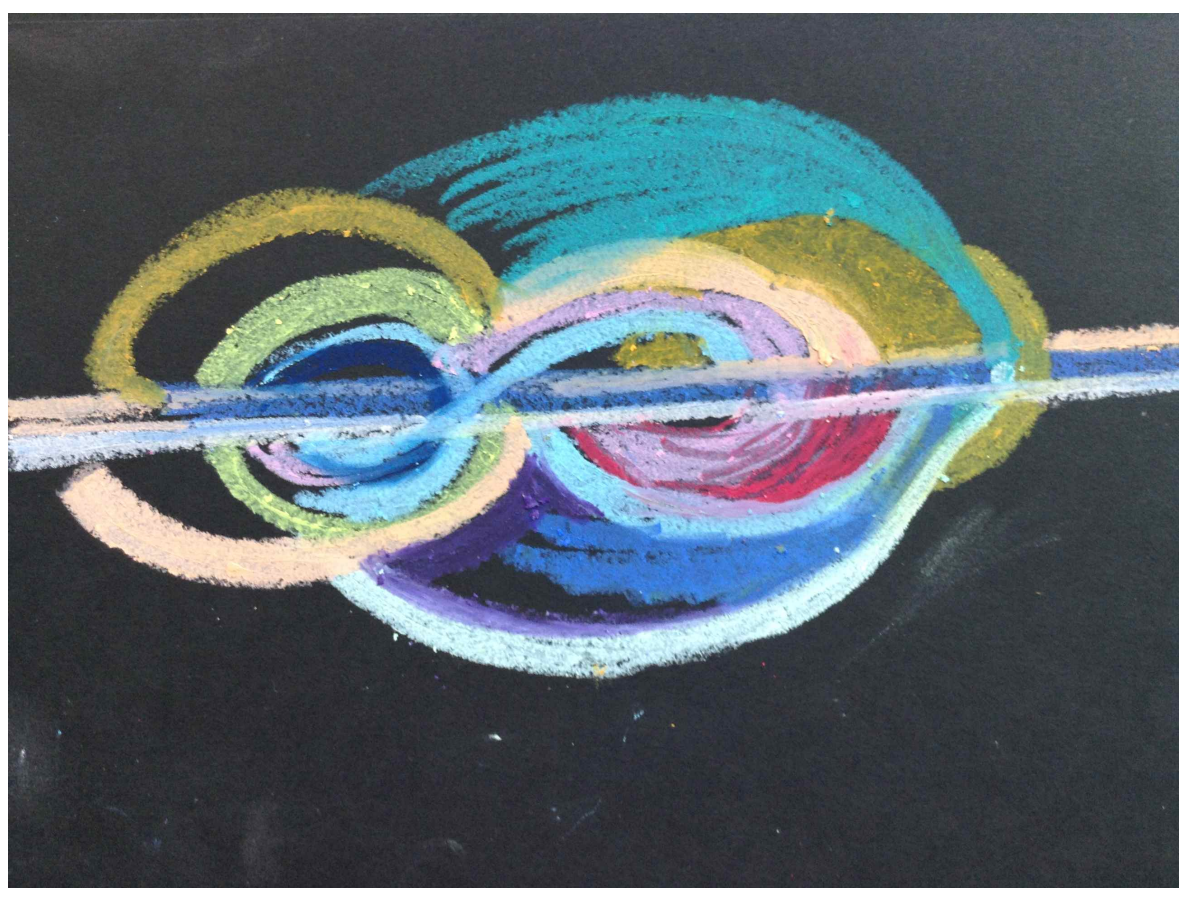

Figure 6. Matilde Marcolli, Biocosmism N.1, 2010.

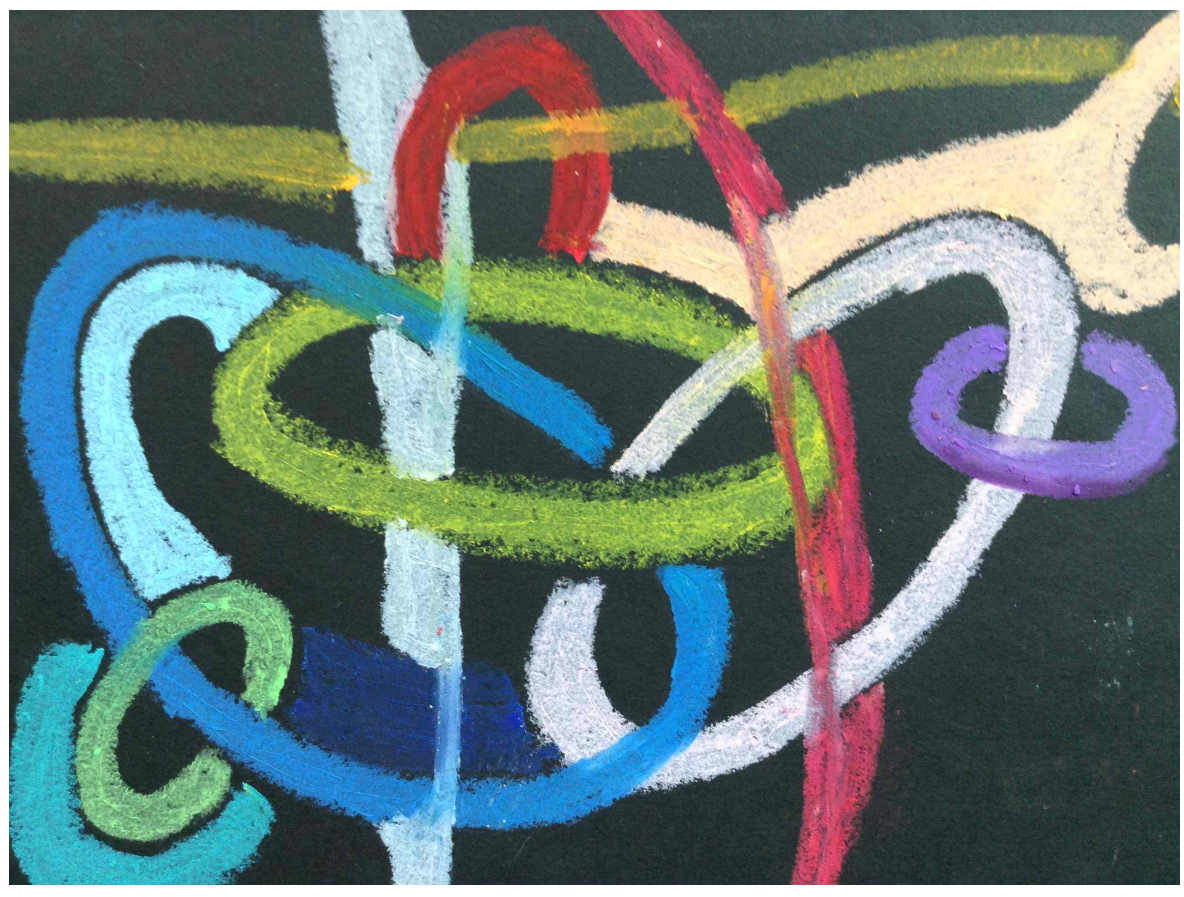

Figure 7. Matilde Marcolli, Biocosmism N.2, 2010. 
their Cosmology department, where I will be visiting for extended periods of time over the next couple of years. Whether mathematical cosmology or computational linguistics will end up as my next field of research is too early to say, but likely it will be something of this sort, further away from the core of traditional subjects in mathematics and theoretical physics.

3.8. Et in Arcadia ego. The general discourse of scientists about science is marred by the old beliefs of the Ancient Greeks in the kalos kai agathos: that which is beautiful must also be good, and conversely. This leads inevitably to portraits of scientists as cartoonish heroes: the more profound and significant the science, the more the scientists tend to be portrayed as fundamentally good and honest human being. The truth, unfortunately, is that not all that is beautiful is also good, and beautiful mathematics can be and often is produced by horrible human beings. The laudable exceptions are few and far between. This removes nothing from the beauty of the mathematics in itself. In fact, what is truly heroic about science is the fact that it does uncover beautiful truths about the universe despite the ugliness and brutality of the human beings involved. Hiding this fact behind the usual hagiographic distortions of reality renders a poor service to science and a poor service to all the human beings who passionately embark on becoming scientists and deserve a more honest warning about both the beauty and the ugliness they are likely to encounter along the way. Most of my artistic productions, from various forms of writings to various forms of visual expression, have largely been aimed at providing what, based on my twenty years of experience as a mathematician, I believe to be a more realistic portrait of our profession.

\section{Eternal Anarchy}

hac in hora sine mora corde pulsum tangite

4.1. La città dolente. My first science fiction novel, City of Sorrow, [3], is closely modeled on the typical action-adventure style of American science fiction. About two thirds of the novel deal with a critical revisiting of certain mythologies of my youth. Italy played a curious role in the Cold War years: while officially part of the NATO block, it was culturally much more closely in the sphere of influence of the Soviet Union than any other Western country. When I grew up, I had easy access to Russian songwriters, Russian movies, Russian poetry, and of course Russian science, as I already discussed. Along with the high culture (Andrei Tarkovsky, Boris Pasternak, Joseph Brodsky, Vladimir Vysotsky, the Strugatsky brothers) came some more dubious artifacts and a considerable amount of mythology, linked closely to the promise of scientific progress and the euphoria of the Space Age. Part of my motivation for writing City of Sorrow was the need for a critical reexamining of these mythologies and of the role that the Cold War had in shaping a generation of aspiring scientists like myself. Behind the action-adventure facade, it also is a critical reflection on Socialism and Anarchism, the complex and multifaceted political space where I generally belong. The last chapter of City of Sorrow, written after I left MIT, has a different flavor: it is much more focused on a criticism of the scientific community as I experienced it in the previous years, with its brutality and fierce territoriality, its exclusion games, and the ultimate betrayal of the dream 


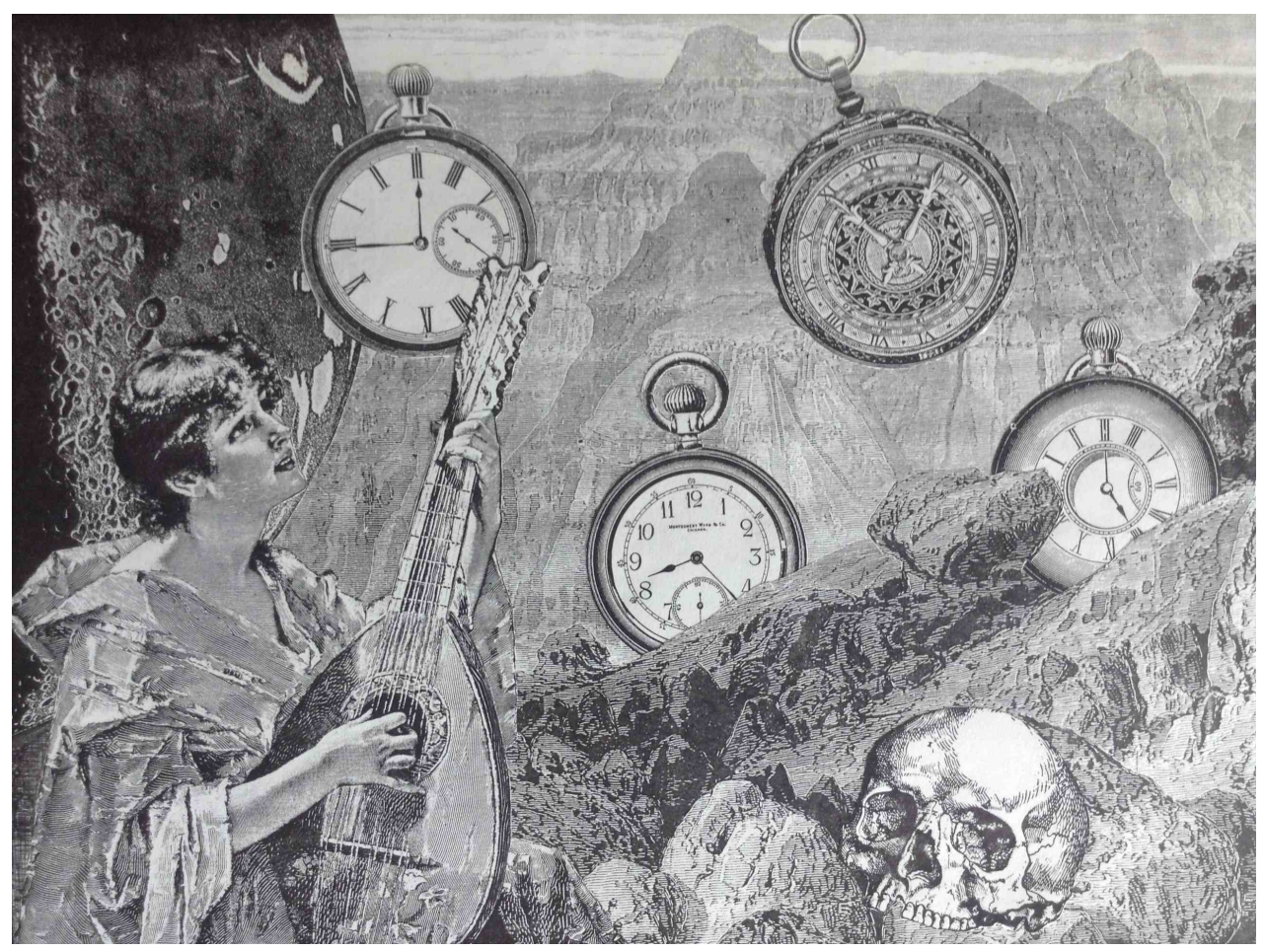

Figure 8. Matilde Marcolli, Et in Arcadia Ego, 1997.

of an open and broad collaborative effort for the benefit of humankind that I grew up believing science to be.

I have a plan for another science fictional depiction of the inner functioning of the mathematical community, Terracotta Warriors, [14], which is still in a very early stage of preparation at the moment, but which will hopefully some day come to completion.

4.2. Dadaist persuasion. During the (in)famous obscenity trial of 1957, Allen Ginsberg's poem "Howl" was referred to as narrating the story of "a drifter of Dadaist persuasion" (in reference to Carl Solomon, to whom Part III of the poem is dedicated). I have adopted this poignant description as an excellent depiction of my twenty years of tortuous itinerary through the mathematical world.

I experimented with poetry only in the recent collection Street Science, [2]. The formal inspiration is recognizably coming from Allen Ginsberg, my favorite English language poet, though my own small stylistic peculiarity lies in not using a graphical subdivision into verses, but a form of hidden versification dictated by the cadence, rhythmic intonation, and frequent alliterations. The subject of the collection, as I discussed in [1], is an overview of my twenty years of mathematical existence, starting at the time of my graduation in Physics in 1993, up until the year 2013, when the poems were written.

Poetry is, in my opinion, the best form of revolutionary art, and it should be reserved for those special moments when one wants to let our a cry of anguish, or 

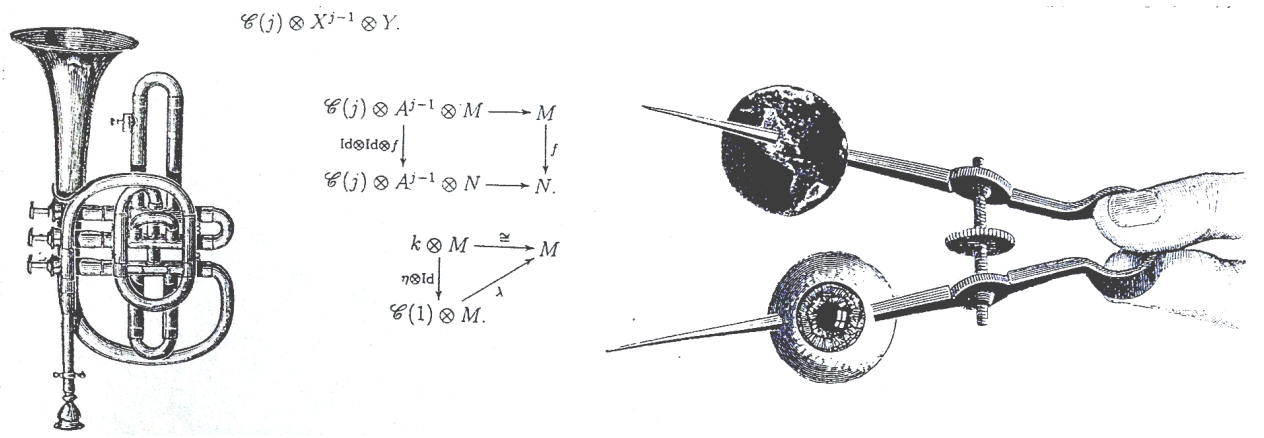

Figure 9. Matilde Marcolli, Chasing, 1996.

a war cry, a howl: a howl in the night, a Whitmanian barbaric yawp over the roofs of the world.

All my other writings have been prose, either novels [3], [4], [14], [15], using the science fictional form as a way of slightly displacing the present in a convenient imaginary future, or prose, as in the short commentaries originating from blog posts, [5], [6], [7], [8].

In my scientific work in Mathematics and in Physics I have been the eternal outsider: a drifter, an anarchist, a ronin. I do not belong to any recognized school or to any recognizable group. I shape shifted my way through those mined fields by constantly being on the move, constantly transforming and reinventing myself into new identities. In my writings and art, I have intentionally chosen a samizdat form, bypassing any sort of official publishing and making everything available through a small online printing press based in Canada. I also personally sell my writings at Anarchist book fairs around California, where I hope to find an audience receptive of my tragicomical experiences with mathematical power structures and their land grabbing games.

Where eldest Night

And Chaos, ancestors of Nature, hold

Eternal anarchy amidst the noise

Of endless wars

(John Milton, "Paradise Lost", II, 894-897)

\section{REFERENCES}

[1] Matilde Marcolli, The Wolf and the Street: Narrative encounters with Mathematics, in "Imagine Math 3: Between Culture and Mathematics" (Editor: Michele Emmer) Springer Verlag, 2014.

[2] Matilde Marcolli, Street Science, Lulu Press, 2013.

[3] Matilde Marcolli, City of Sorrow, Lulu Press, 2014.

[4] Matilde Marcolli, Yamaon, Lulu Press, 2014.

[5] Matilde Marcolli, Heart in the Machine, Lulu Press, 2013.

[6] Matilde Marcolli, Screams of Metal, Lulu Press, 2013.

[7] Matilde Marcolli, Listening to Golem, Lulu Press, 2013.

[8] Matilde Marcolli, In the Wells of Silence, Lulu Press, 2013. 
[9] Matilde Marcolli, The Somber Science, Lulu Press, 2013.

[10] Matilde Marcolli, Racconti per il Lupo. Matematica e altre fantasie, Lulu Press, 2012.

[11] Matilde Marcolli, Still Life as a Model of Spacetime, lecture at Century Books, Pasadena, 2012; Lulu Press, 2013.

[12] Matilde Marcolli, The Void in Modern Art and Modern Science, lecture at Century Books, Pasadena, 2014.

[13] Matilde Marcolli, Voyage through the Night: Opus Rubrum, in preparation.

[14] Matilde Marcolli, Terracotta Warriors, in preparation.

[15] Matilde Marcolli, The Rape of Europa and the Mirror of Narcissus, in preparation.

[16] Matilde Marcolli, Encounters: a narrated library, in preparation.

[17] Matilde Marcolli, The illegal practice of cosmology, in preparation. 